12

\title{
Умеренно релятивистский генератор микроволнового излучения субгигаваттного уровня типа твистрон с эффективностью $50 \%$
}

\author{
() Е.М. Тотьменинов, С.А. Кицанов, А.И. Климов, А.Н. Синяков \\ Институт сильноточной электроники СО РАН, Томск, Россия \\ E-mail: totm@Ife.hcei.tsc.ru
}

Поступило в Редакцию 19 декабря 2018г.

В окончательной редакции 19 декабря 2018 г.

Принято к публикации 24 декабря 2018 г.

\begin{abstract}
Путем оптимизации электронно-волнового взаимодействия в эксперименте получен режим квазистационарной генерации умеренно релятивистского СВЧ-генератора типа твистрон с эффективностью преобразования мощности электронного пучка в электромагнитное излучение $50 \pm 20 \%$. Для параметров электронного пучка (напряжение на диоде $210 \mathrm{kV}$, ток пучка $1.36 \mathrm{kA}$ ) мощность микроволновой генерации составила $140 \pm 40 \mathrm{MW}$ на частоте $10.63 \mathrm{GHz}$ при ведущем магнитном поле около 1.9 Т. Длительность микроволновых импульсов составила около $16 \mathrm{~ns}$.
\end{abstract}

DOI: 10.21883/PJTF.2019.06.47501.17648

Наличие в структуре энергообмена предварительной модуляции, которая задает амплитудно-фазовые соотношения между электронным пучком и возбуждаемым электромагнитным полем, расширяет круг режимов работы релятивистских черенковских СВЧ-генераторов. Путем управления этими соотношениями получены плавная перестройка частоты СВЧ-генерации в пределах $10 \%$ и длительности СВЧ-сигнала в релятивистской лампе обратной волны с модулирующим рефлектором [1], а также достигнута эффективность около $20 \%$ релятивистского черенковского СВЧ-генератора без ведущего магнитного поля [2]. Вместе с тем остается актуальной задача повышения эффективности черенковских приборов, генерирующих мощные СВЧ-импульсы в десятки наносекунд [3]. Ориентиром при этом может служить эффективность 60\% и выше, полученная в нерелятивистских приборах [4]. Предпосылки в данном направлении созданы в теоретической работе, посвященной ультрарелятивистскому твистрону-усилителю [5]. В ней показано, что эффективность такого прибора, в котором область энергоотбора отделена от области модуляции пучка участком инерционной группировки, достигает $\approx 60 \%$. Данный подход нашел подтверждение в численном эксперименте [6] для относительно небольшой энергии электронов (около $200 \mathrm{keV}$ ) с использованием РІС-кода KARAT [7]. Было показано, что на основе модернизированной схемы релятивистской лампы обратной волны с модулирующим рефлектором при соответствующем подборе амплитудно-фазовых соотношений реализуется структура энергообмена, близкая к описанной в [5]. Эффективность преобразования мощности электронного пучка в электромагнитное излучение в таком твистронегенераторе составила 55\%.

Цель настоящей работы состоит в экспериментальном исследовании рассчитанного в [6] твистрона-генератора для частотного диапазона $10.0 \mathrm{GHz}$.
Генератор с магнитной системой и электронным пучком схематично представлен на рис. 1. Место высадки электронного пучка (точка $A$ ) выбрано вблизи области максимальной компактности электронного сгустка, чтобы не допустить его разрушения под действием сил объемного заряда. Амплитудно-фазовые соотношения в генераторе таковы, что электронный сгусток, предварительно сформированный в результате модуляции электронов по скорости в области резонансного рефлектора, вблизи места высадки оказывается в тормозящей фазе высокочастотного (ВЧ) поля. Поле представлено синфазной суммой двух основных гармоник (0)-й попутной и (-1)-й встречной волны, у которых сопротивления

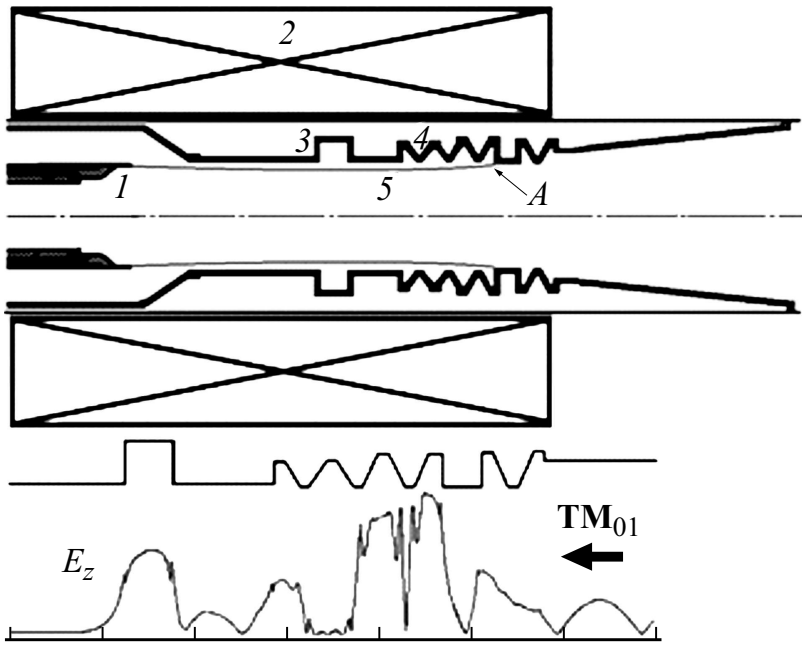

Рис. 1. Схема твистрона-генератора: 1 - кромочный взрывоэмиссионный катод и катододержатель, 2 - импульсный соленоид, 3 - модулирующий рефлектор, 4 - замедляющая система, 5 - электронный пучок, $A$ - место высадки электронного пучка. Внизу представлено „холодное“ продольное распределение компоненты $E_{z}$ электрического поля на радиусе пучка для частоты $10.63 \mathrm{GHz}$. 


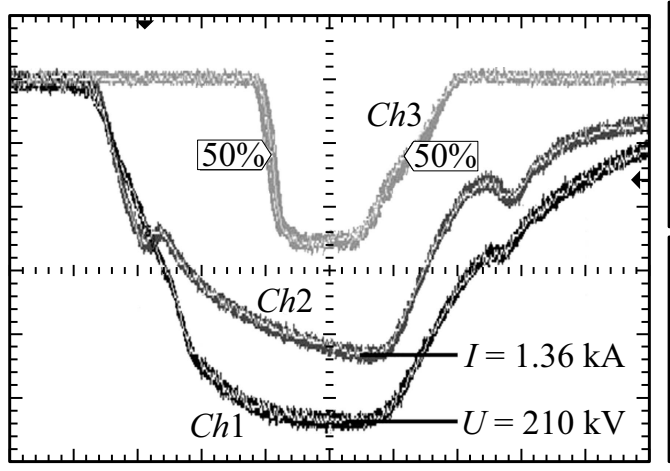

Ch1 $40.0 \mathrm{kV}$ Ch3 $50.0 \mathrm{mV} M 10.0 \mathrm{~ns} 5.0 \mathrm{GS} / \mathrm{s}$ Ch2 $300 \mathrm{~A} \quad \mathrm{Neg} \operatorname{Wid}(\mathrm{Ch} 3) 20.82 \mathrm{~ns}$

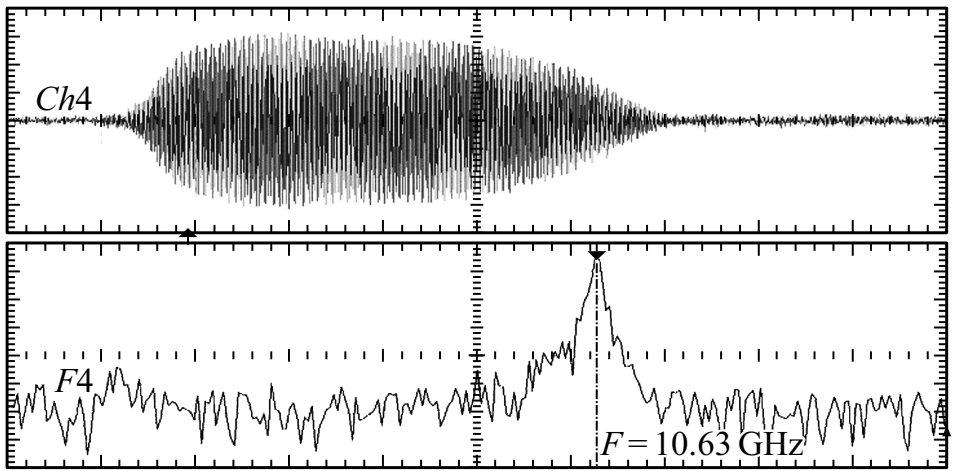

Ch4 $18.0 \mathrm{mV} / \mathrm{div}$ F4 FFT(Ch4) $10.0 \mathrm{~dB} / \mathrm{div} 500 \mathrm{MHz} / \mathrm{div}$

Рис. 2. Пакет из 20 последовательных импульсов напряжения на диоде $(C h 1)$, тока диода $(C h 2)$, детектированных СВЧ-сигналов $(C h 3)($ a) и осциллограмма радиосигнала $(C h 4)$ и его спектр $(F 4)(b) . F=10.63 \mathrm{GHz}$.
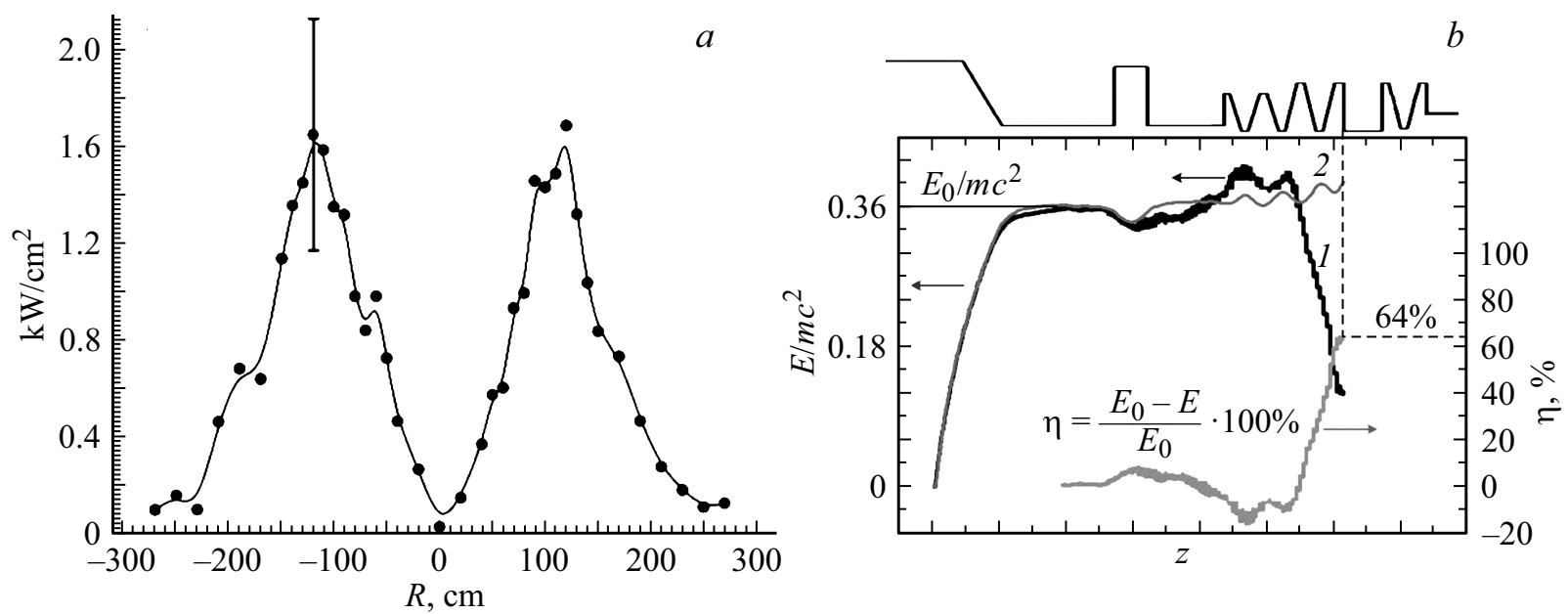

Рис. 3. Пространственное распределение плотности потока мощности, измеренное на расстоянии 600 ст от апертуры излучающей антенны $(a)$, и результат численного моделирования [5] для режима с эффективностью $55 \%(b): E / m c^{2}-$ усредненная за период ВЧ-колебаний нормированная кинетическая энергия электронов $(1-$ в режиме квазистационарной СВЧ-генерации, $2-$ в отсутствие генерации) и „электронный КПД“ генератора $(\eta)$.

связи с пучком составляют $Z_{0} \approx 3.3 \Omega, Z_{-1} \approx 2.5 \Omega$ соответственно [6]. Таким образом, эффективный энергоотбор осуществляется на достаточно коротком участке замедляющей системы с длиной, равной периоду гофры (рис. 1). Отработанный электронный пучок сразу же высаживается на поверхность электродинамической структуры. Следствие этого - малое количество обратных электронов, вклад которых в структуру энергообмена в общем случае является неконтролируемым.

Эксперимент был выполнен с использованием сильноточного ускорителя электронов „СИНУС-7“ [8], длительность импульса напряжения которого составляла около $50 \mathrm{~ns}$ при длительности фронта около $20 \mathrm{~ns}$. Для вывода излучения в открытое пространство использовался конический рупор с диаметром излучающей апертуры $350 \mathrm{~mm}$. СВЧ-сигнал принимался антенной в виде открытого конца прямоугольного волновода сечением
$23 \times 10 \mathrm{~mm}$ с поглотителями на внешней части для уменьшения зависимости эффективной площади антенны от частоты. Погрешность измерения эффективной площади составляла $\pm 20 \%$. Сигнал передавался в экранированное помещение с помощью кабеля РК50-4-47, детектировался полупроводниковым детектором и регистрировался осциллографом Tektronix TDS-7404. Погрешность калибровки передающей трассы составляла $\pm 7 \%$, а детектора - $\pm 20 \%$. При измерении спектра генерации радиосигнал регистрировался осциллографом LeCroy WaveMaster 830Zi. Ведущее магнитное поле создавалось импульсным соленоидом с длиной намотки около $260 \mathrm{~mm}$ и индукцией $1.9 \mathrm{~T}$.

Для параметров электронного пучка, близких к расчетным: напряжение на диоде $210 \pm 20 \mathrm{kV}$, ток пучка генератора $1.36 \pm 0.07 \mathrm{kA}$, были получены импульсы СВЧ-излучения на частоте $10.63 \mathrm{GHz}$ (рис. 2). Длитель- 
ность излучения по уровню 0.5 от максимальной мощности составила $\approx 16 \mathrm{~ns}$. В пределах пачки (рис. 3, $a$ ) стандартное отклонение СВЧ-мощности не превышало $\pm 5 \%$. Мощность СВЧ-излучения, полученная путем интегрирования пространственного распределения плотности потока мощности (рис. 3, $a$, рабочий тип волны $\mathrm{TM}_{01}$ ), составила $140 \pm 40 \mathrm{MW}$. Это соответствует эффективности преобразования мощности электронного пучка (произведение напряжения на диоде и тока пучка) в электромагнитное излучение $50 \pm 20 \%$. На основе проведенного ранее численного моделирования [6] можно сделать оценку „электронного“ КПД генератора $(\eta)$, рассчитанного по изменению кинетической энергии электронов пучка относительно их начальной энергии в канале перед рефлектором. Для эффективности 50\% значение $\eta$ можно оценить величиной около $60 \%$ (рис. $3, b$ ), т.е. в процессе взаимодействия электроны пучка теряют в среднем более половины своей начальной энергии.

Отметим, что расположение места высадки электронного пучка в области максимума напряженности электрического поля может стимулировать процессы, приводящие к ухудшению условий генерации [9]. Однако формы СВЧ-сигналов и близкая к расчетной эффективность генератора свидетельствуют о том, что в условиях эксперимента эти факторы не проявлялись.

Проведенное экспериментальное исследование показывает, что на базе твистрона-генератора и компактного сильноточного электронного ускорителя возможно создание высокоэффективных источников микроволнового излучения с мощностью $\sim 10^{8} \mathrm{~W}$, предназначенных для лабораторных исследований, а возможно, и для решения различных прикладных задач. Для работы таких СВЧ-источников важно, что существенное уменьшение энергии частиц в отработавшем электронном пучке снижает уровень тормозного рентгеновского излучения и соответственно требования к радиационной защите обслуживающего персонала.

Авторы выражают благодарность С.Е. Острижных за помощь в проведении эксперимента, а также региональному центру коллективного пользования Томского научного центра СО РАН за возможность использования осциллографа LeCroy WaveMaster 830Zi.

\section{Список литературы}

[1] Коровин С.Д., Куркан И.К., Ростов В.В., Тотьменинов Е.M. // Изв. вузов. Радиофизика. 1999. Т. 42. В. 12. C. $1189-1196$.

[2] Totmeninov E.M., Kitsanov S.A., Vykhodtsev P.V. // IEEE Trans. Plasma Sci. 2011. V. 39. N 4. Pt 2. P. 1150-1153.

[3] Yang D., Shi Y., Xiao R., Teng Y., Sun J., Chen C. // AIP Adv. 2018. V. 8. P. 095229.

[4] Teryaev V.E., Shchelkunov S.V., Jiang Y., Hirshfield J.L. // AIP Conf. Proc. 2017. V. 1812. P. 060004.

[5] Ковалёв Н.Ф., Петелин М.И., Райзер М.Д., Сморгонский А.В. // Релятивистская высокочастотная электроника. Горький: ИПФ АН СССР, 1979. С. 76-113.
[6] Тотьменинов Е.М. // Изв. вузов. Физика. 2017. Т. 60. № 8. C. $61-64$.

[7] Тараканов В.П. // Математическое моделирование. Проблемы и результаты. М.: Наука, 2003. С. 456-476.

[8] Mesyats G.A., Korovin S.D., Gunin A.V., Gubanov V.P., Stepchenko A.S., Grishin D.M., Landl V.F., Alekseenko P.I. // Laser Part. Beams. 2003. N 21. P. 197-209.

[9] Korovin S.D., Mesyats G.A., Pegel I.V., Polevin S.D., Tarakanov V.P. // IEEE Trans. Plasma Sci. 2000. V. 28. N 3. P. 485-495. 